\title{
First report of Sclerotium delphinii on Cynanchum Paniculatum
}

\author{
Jing Wang ${ }^{1} \cdot$ Baomei Zhao ${ }^{1} \cdot$ Chunju Liu $^{1} \cdot$ Huixiang Liu ${ }^{1} \cdot$ Aixin Liu ${ }^{1}$
}

Received: 3 November 2016 / Accepted: 17 March 2017 / Published online: 20 April 2017

(C) Australasian Plant Pathology Society Inc. 2017

\begin{abstract}
In August 2013, a severe disease that caused collar rot of Cynanchum paniculatum plants was observed in Shandong province, China. Diseased stems were watersoaked, grey-green or light brown in color, and displayed both silky mycelium and numerous tan or reddish brown sclerotia on the basal part of the stems and the surrounding soil. Based on morphological traits and molecular analysis of the internal transcribed spacer sequences, the casual agent was identified to be Sclerotium delphinii, and its pathogenicity was confirmed on healthy potted seedlings of $C$. paniculatum. Thus, the present study represents the first report of $S$. delphiniiinfection of $C$. paniculatum both in China and internationally.
\end{abstract}

Keywords Medical plant $\cdot$ Collar rot $\cdot$ Internal transcribed spacer

Cynanchum paniculatum is a common perennial herbaceous plant in China, where its roots have long been widely used for the treatment of rheumatoid arthritis, lumbago, abdominal pain, and traumatic injuries (Choi et al. 2006). Wild C. paniculatum grows mainly in the Liaoning, Hebei, Henan, Gansu and Shandong Provinces of China. The increasing demand of pharmaceuticals derived from C. paniculatum has led to both the over-exploitation of wild plants, and the initiation of commercial C. paniculatum cultivation in many areas of China (Lee et al. 2003; Dou et al. 2007; Min et al. 2010).

Aixin Liu

liuax@sdau.edu.cn

1 Department of Plant Pathology, Shandong Agricultural University, Taian 271018, China
In August 2013, a novel, destructive disease was observed on C. paniculatum plants in commercial fields in the Xintai and Pingyi counties of Shandong province (Fig. 1a). The incidence of the disease was found to be high in these areas, particularly in low-lying fields. Diseased stems were watersoaked and grey-green or light brown in color; in addition, silky mycelium and numerous tan or reddish brown sclerotia were observed on the basal part of the stems and the surrounding soil (Fig. 1b, c). As a result, the roots of infected plants were eventually destroyed, and the epidermis was completely rotted off (Fig. 1d). The disease developed and spread rapidly during the rainy season (July-August) with patches of wilt plants appearing across infected fields.

The putative pathogen was isolated via direct transfer of sterilized sclerotia and stem sections to Petri dishes containing potato dextrose agar (PDA) supplemented with $0.03 \%$ strepyomycin. Individual sclerotium and basal stem fragments were surface-sterilized by successive immersion in $70 \%$ ethanol and $0.1 \%$ mercury dichloride for $30 \mathrm{~s}$, rinsed three times in sterilized water, dried, and then transfered onto PDA plates (Liu et al. 2014). The plates were maintained at $25^{\circ} \mathrm{C}$ for $2-5$ days in the dark. Hyphal tips obtained from the resultant colonies were transferred to fresh PDA plates to obtain pure isolates. In total, 13 pure isolates exhibiting similar growth pattern were obtained and maintained on PDA slants for further analysis.

The entire surface of the Petri plate became covered with a white cotton-like mycelium after three days of incubation, in the dark, at $25{ }^{\circ} \mathrm{C}$. White, spherical sclerotial bodies were initially observed after five days, becoming reddish-brown and reaching $0.6-4.0 \mathrm{~mm}$ in diameter with time (Fig. 2). Based on these morphological characteristics the fungus was identified as belonging to the genus Sclerotium (Okabe and Matsumoto 2003; Xu et al. 2010).

For molecular identification the internal transcribed spacer (ITS) region was amplified by PCR. Isolate Bai2 was cultured 
Fig. 1 Symptoms of basal stem and root rot in Cynanchum paniculatum. a Patches of diseased plants in a field. $\mathbf{b}$ Sclerotia and mycelium of Sclerotium delphinii on surfaces of Cynanchum paniculatum stems, and c surrounding soil. d Rotted Cynanchum paniculatum radix and stems
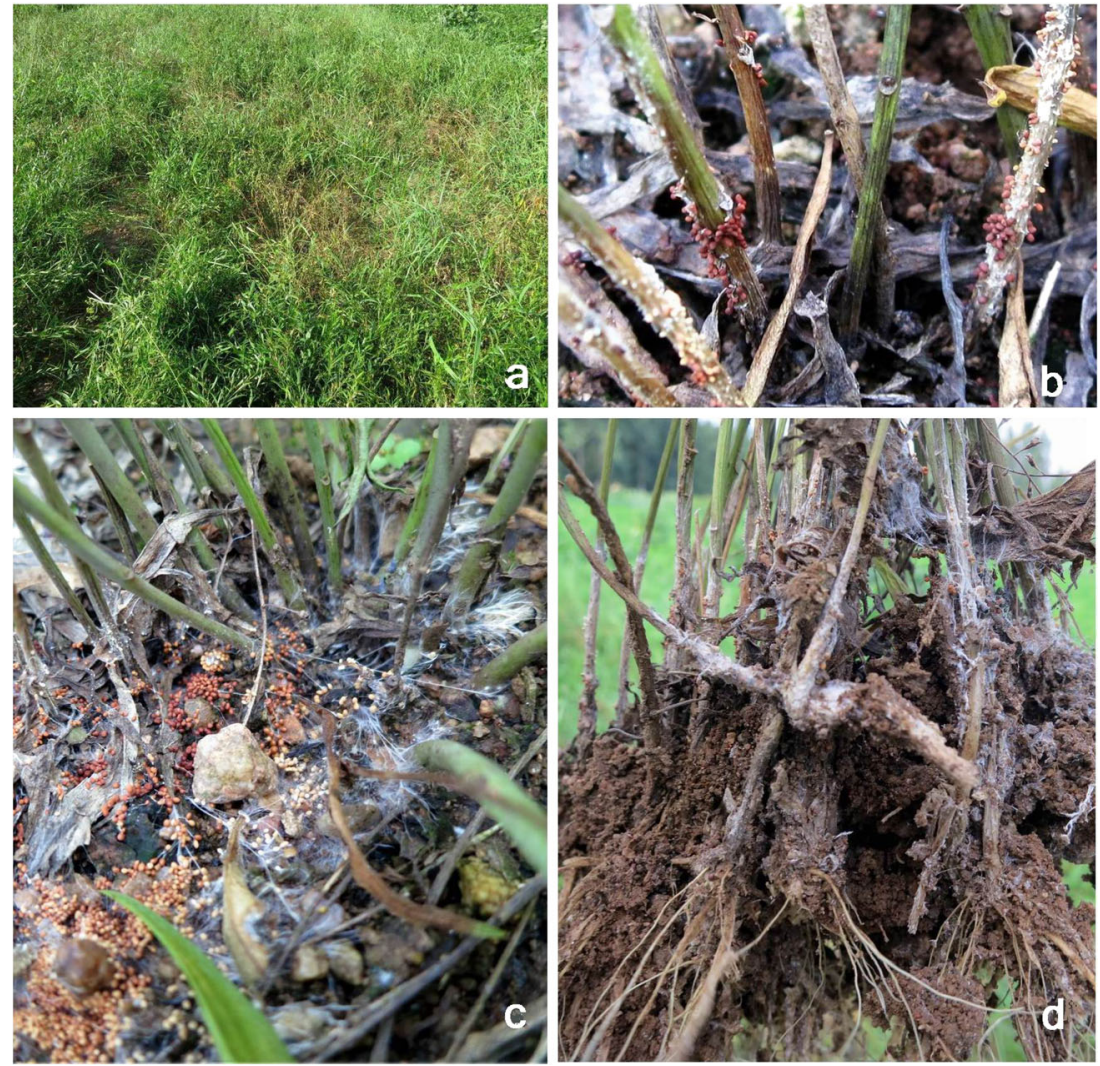

in potato dextrose broth (PDB) for $4-5$ days at $25^{\circ} \mathrm{C}$, and the resulting mycelial mat was harvested. Total genomic DNA was extracted using the CTAB protocol (He 2000), whereby a 682-bp DNA fragment was amplified using the universal primer pair, ITS 1 (5'-TCCGTAGGTGAACCTGCGG-3') and ITS 4 (5'-TCCTCCGCTTATTGATATGC-3') (White et al. 1990). PCR was performed in a Bio-Rad MyCycler



Fig. 2 Sclerotia of Sclerotium delphinii produced on PDA medium after five days of incubation, in the dark, at $25^{\circ} \mathrm{C}$
(Hercules, CA, USA) in a total reaction volume of $25 \mu \mathrm{L}$. The PCR mixture contained $2.5 \mu \mathrm{L}$ of $10 \times$ EasyTaq reaction buffer $\mathrm{Mg}^{2+}$ plus, $2 \mu \mathrm{L}$ of each deoxynucleoside triphosphate (dNTP), $1 \mu \mathrm{L}$ of gDNA, $0.5 \mu \mathrm{L}$ of EasyTaq DNA polymerase (TransGen Biotech, Beijing, China), and $1 \mu \mathrm{L}$ of each primer. The PCR conditions for ITS were $3 \mathrm{~min}$ at $95^{\circ} \mathrm{C}$, followed by 30 cycles of $95^{\circ} \mathrm{C}$ for $30 \mathrm{~s}, 55^{\circ} \mathrm{C}$ for $40 \mathrm{~s}, 72^{\circ} \mathrm{C}$ for $1 \mathrm{~min}$, and a final extension at $72{ }^{\circ} \mathrm{C}$ for $10 \mathrm{~min}$. The resulting ITS sequence of the 682-bp PCR product showed 99\% homology with both Sclerotium rolfsii and Sclerotium delphinii, according to the GenBank database. Sequence alignments were made by ClustalW in MEGA 5.1 and a phylogenetic analysis was conducted using MEGA 5.1 software to confirm the isolate identity. The phylogenetic relationships of isolate Bai2 with closely related taxa was analyzed using the Neighborjoining method. The genetic distances were calculated by the maximum composite likelihood method and phylogeny was assessed using bootstrap analysis with 1000 replicates. In phylogenetic trees, isolate Bai2 clustered into Sclerotium delphinii clade (Fig. 3). Although the ITS sequence of the cultured specimen showed $99 \%$ sequence homology with both S. rolfsii and S. delphinii, based on the phylogenetic analysis results, as showed in Fig. 3, our specimen was identified as being $S$. delphinii (Punja and Damiani 1996). The ITS sequence of the Bai2 isolate was deposited in the GenBank database (accession number KJ552090), and a representative 
Fig. 3 Phylogenetic tree inferred from analysis of internal transcribed spacer sequences using the neighbor-joining method, showing the closest known relatives of Sclerotium delphinii. The numbers on the branches are bootstrap (confidence) values, (expressed as percentage of 1000 replicates). Sequence obtained in the present study is boldtexted. Scleritium coffeicola is used as an outgroup

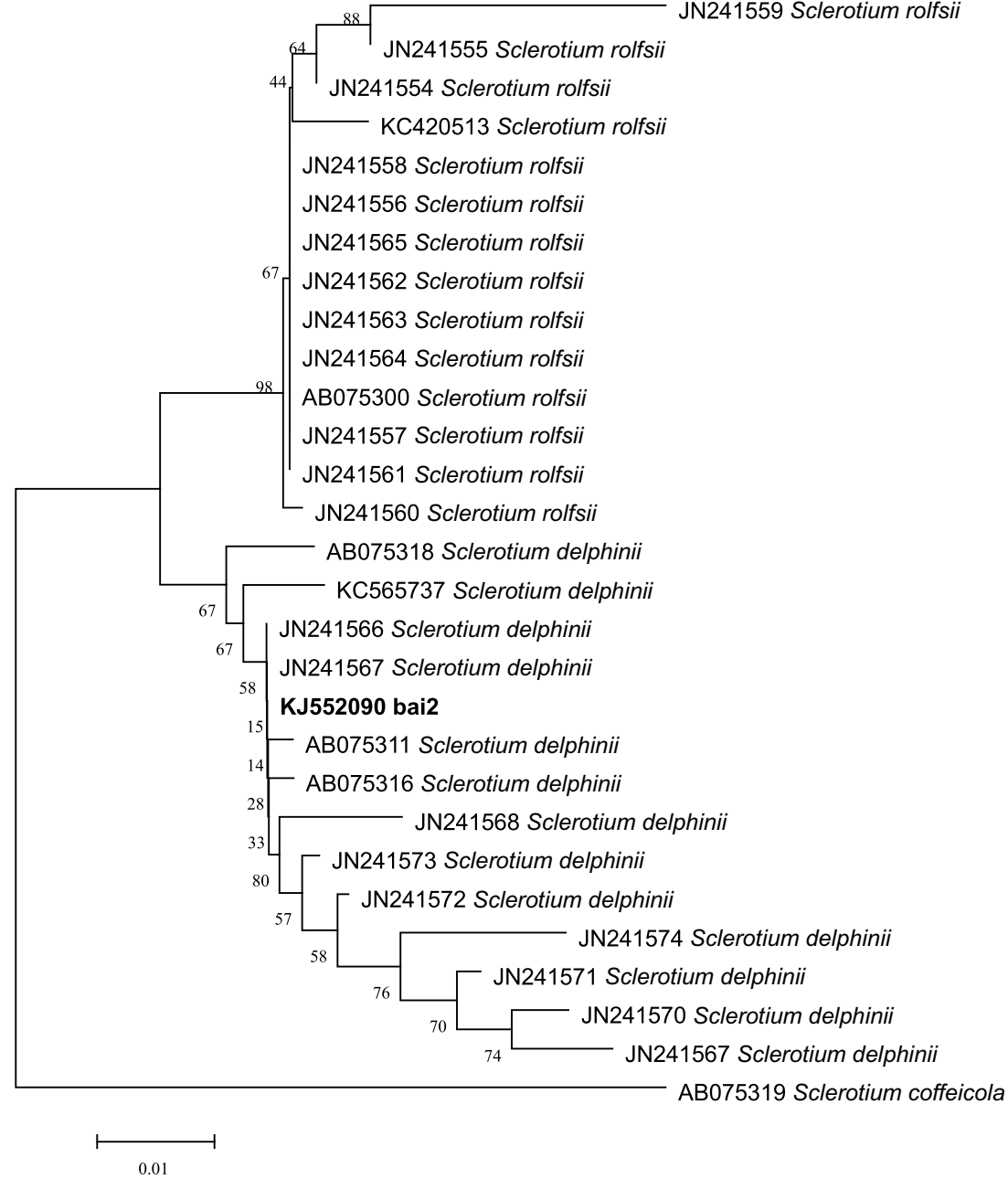

These disease symptoms exhibited by the inoculated plants were identical to those originally observed in the field. The

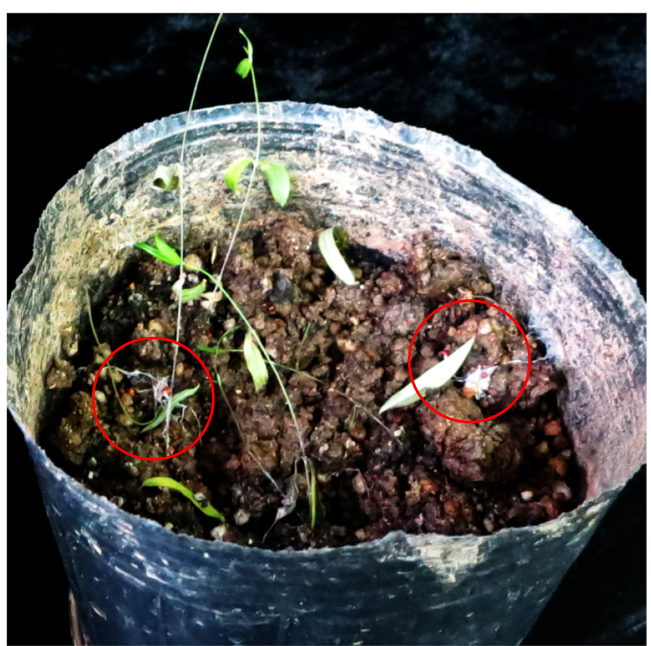

Fig. 4 Infected Cynanchum paniculatum seedling, showing formation of sclerotial bodies on the soil surface seven days after inoculation. Circles show the mycelium and sclerotia in disease stems and surrounding soil sclerotia were observed on the plants and soil surface (Fig. 4). 
control plants remained healthy. Koch's postulates were confirmed via re-isolation of the fungal pathogen, and its comparison with the original isolate.

Sclerotium delphinii (syn. Sclerotium rolfsii var. delphinii) has been reported as being pathogenic in many herbaceous plants (Xu et al. 2008; Farr and Rossman 2016) and predominantly causing stem and collar rot, with brown sclerotia occurring on the surface of infected tissues (Mukherjee et al. 2015). The present study represents the first worldwide report of S. delphinii causing collar rot on C. paniculatum.

Acknowledgement This work was financially supported by Modern Aricultural Industry Technology in Shandong Province, China (SDAIT20-04).

\section{References}

Choi JH, Jung BH, Kang OH, Choi HJ, Park PS, Cho SH, Kim YC, Sohn DH, Park H, Lee JH, Kwon DY (2006) The anti-inflammatory and anti-nociceptive effects of ethyl acetate fraction of Cynanchi paniculati radix. Biol Pharm Bull 29:971-975

Dou J, Li P, Bi ZM, Zhou JL (2007) New C21 steroidal glycoside from Cynanchum paniculatum. Chin Chem Lett 18:300-302

Farr DF, Rossman AY (2016) Fungal databases, systematic mycology and microbiology laboratory, ARS, USDA. http://nt.ars-grin. gov/fungaldatabases. Retrieved 1 November 2016

He YQ (2000) An improved protocol for fungal DNA preparation. Mycosystema 19:434
Lee SK, Nam KA, Heo YH (2003) Cytotoxic activity and G2/M cell cycle arrestmediated by antofine, a phenanthroindolizidine alkaloid isolated from Cynanchum paniculatum. Planta Med 69:21-25

Liu AX, Li Z, Wang ZM, Liang YC, Zhu XP (2014) Identification of Rhizoctonia solani AG1-IB as a causal agent of leaf blight in Cynanchum paniculatum in China. J Gen Plant Pathol 80:94-98

Min HY, Chung HJ, Kim EH, Kim S, Park EJ, Lee SK (2010) Inhibition of cell growth and potentiation of tumor necrosis factor- $\alpha$ (TNF- $\alpha)$ induced apoptosis by a phenanthroindolizidine alkaloid antofine in human colon cancer cells. Biochem Pharmacol 80:1356-1364

Mukherjee AK, Mukherjee PK, Kranthi S (2015) Identification of Sclerotium delphinii causing seedling rot in cotton. J Plant Pathol 97:303-305

Nitzan N, Chaimovitsh D, Davidovitch-Rekanati R (2012) Rhizoctonia web blight-a new disease on mint in Israel. Plant Dis 96:370-378

Okabe I, Matsumoto N (2003) Phylogenetic relationship of Sclerotium rolfsii (teleomorph Athelia rolfsii) and $S$ delphinii based on ITS sequences. Mycol Res 107:164-168

Punja ZK, Damiani A (1996) Comparative growth, morphology, and physiology of three Sclerotium species. Mycologia 88:694-706

White TJ, Bruns T, Lee S, Taylor J (1990) Amplification and direct sequencing of fungal ribosomal RNA genes for phylogenetics. In: Innis MA, Gelfand DH, Sninsky JJ, White TJ (eds) PCR protocols: a guide to methods and applications. Acad Press, New York, pp 315-322

$\mathrm{Xu}$ Z, Gleason ML, Mueller DS, Esker PD, Bradley CA, Buck JW, Benson DM, Dixon PM, Monteiro JEBA (2008) Overwintering of Sclerotium rolfsii and $S$. rolfsii var. delphinii in different latitudes of the United States. Plant Dis 92:719-724

Xu Z, Harrington TC, Gleason ML, Batzer JC (2010) Phylogenetic placement of plant pathogenic Sclerotium species among teleomorph genera. Mycologia 102:337-346 